Revista ADM.MADE - Revista do Mestrado em Administração e Desenvolvimento Empresarial

Universidade Estácio de Sá - Rio de Janeiro

ISSN 2237-5139

\title{
Risco nos Contratos de Transbordo dos Terminais Intermodais da Logística de Grãos do Brasil
}

\author{
Diogo Palheta Nery ${ }^{1}$ \\ Renato Luiz Sproesser ${ }^{2}$ \\ Silvia Morales de Queiroz Caleman ${ }^{3}$ \\ Renata Giovinazzo Spers ${ }^{4}$
}

\begin{abstract}
Alguns dos problemas encontrados nas operações dos terminais intermodais localizam-se na contratação das transações de transbordo das cargas, como o risco de uma das partes envolvidas na transação querer agir de forma oportunista, prejudicando a outra parte. As transações que envolvem investimentos em ativos específicos estão mais sujeitas ao risco de oportunismo. Desse modo, é recomendável que os contratos dessas transações contenham salvaguardas para proteger ambas as partes. A presente pesquisa teve, como objetivo, descrever a situação de risco no contrato de transbordo principal dos terminais intermodais da cadeia logística de grãos do Brasil. A amostra da pesquisa foi composta por 22 terminais intermodais brasileiros. A análise dos dados foi realizada utilizando-se uma tabela de contingência. Apurou-se que a maioria das transações que continham investimentos em ativos específicos estava protegida com salvaguardas, e que os contratantes dos serviços de transbordo de grãos estão mais expostos ao risco de oportunismo do que os terminais contratados. Não foi observado o esquema de contratação proposto na literatura, o que sugere que as partes dessas transações de transbordo de cargas procuram se proteger de outro risco diferente do problema de hold up.
\end{abstract}

Palavras-chave: Logística intermodal, Agronegócio, Williamson, Contratos.

\section{Risk in the Transshipment Contracts in the Intermodal Terminals of Grain Logistics in Brazil}

Some of the problems found in the operations of intermodal terminals are in hiring cargoes transhipment transaction. For instance, a party involved in the transaction may want to act opportunistically, harming the other party. Transactions involving investments in specific assets are more at risk of opportunism. Thus, it is recommended that the contracts of these transactions contain safeguards to protect both parties. The aim of this study was to describe the risk in the contract of main transshipment of intermodal terminals' of the logistic chain of grains in Brazil. The research sample was composed of twenty-two Brazilian intermodal terminals. Data analysis was performed using a contingency table. It was found that most of the transactions that contained investments in specific assets were protected with safeguards, and also that contractors of grain transshipment services are more exposed to the risk of opportunism than hired terminals. The contracting schema suggested in the literature was not found in analyzed data, which might be because the parties of these transactions seek to protect against other kind of risks instead of hold-up ones.

Keywords: Intermodal Logistics, Agribusiness, Williamson, Contracts.

\footnotetext{
${ }^{1}$ Mestre e Graduado em Administração, Universidade Federal de Mato Grosso do Sul (UFMS). Doutorando em Administração, Faculdade de Economia, Administração e Contabilidade da Universidade de São Paulo (FEA-USP). Endereço: Av. Prof ${ }^{\circ}$. Luciano Gualberto, 908 - Butantã - CEP: 05508-010 - São Paulo, SP. Email: dpnery @usp.br.

2 Doutor em Engenharia de Sistemas Industriais pelo Instituto Nacional Politécnico de Lorraine - França. Professor do Programa de Pós-Graduação em Administração da Universidade Federal de Mato Grosso do Sul. Endereço: ESAN/UFMS, Cidade Universitária, Caixa Postal 549. CEP 79070-900 - Campo Grande, MS. Email:renato.sproesser@ufms.br.

${ }^{3}$ Doutora em Administração pela Faculdade de Economia, Administração e Contabilidade da Universidade de São Paulo (FEA/USP). Docente da Escola de Administração e Negócios da Universidade Federal de Mato Grosso do Sul (ESAN/UFMS). Docente Pesquisadora do Programa de Pós Graduação em Administração da Universidade Federal de Mato Grosso do Sul (PPGAd/UFMS). Endereço: Av. Senador Filinto Muller S/N - Unidade 10A - Cidade Universitária - CEP: 79070-900 - Campo Grande/MS - Brasil. E-mail: silvia.caleman@ufms.br..

${ }^{4}$ Doutora em Administração pela Faculdade de Economia, Administração e Contabilidade - FEA - USP. Professora Associada do Programa de PósGraduação em Administração da FEA - USP. Endereço: Av. Prof. Luciano Gualberto, 908 - Sala G163 - CEP 05089-010 - São Paulo - SP. Email: renatag@usp.br.
}

http://dx.doi.org/10.21714/2237-51392017v21n2p017029

Artigo recebido em 15/04/2017 e aprovado em 30/09/2017. Artigo avaliado em double blind review.

Editor responsável: Marco Aurélio Carino Bouzada 


\section{Introdução}

O agronegócio é um dos setores mais importantes da economia brasileira. Em 2015, o Produto Interno Bruto (PIB) desse setor foi de $R \$ 1,280$ trilhão, representando $21,35 \%$ do PIB brasileiro naquele ano (CEPEA, 2015). O agronegócio também tem sido o principal responsável pelo superávit da balança comercial brasileira nos últimos anos (MAPA, 2012).

A produção de grãos se destaca no agronegócio do país. As maiores culturas são as de soja e de milho, cujas produções alcançaram 75,3 milhões e 57,4 milhões de toneladas, respectivamente, na safra 2010/11 (CONAB, 2012).

Além da produção agropecuária, o agronegócio compreende as atividades de produção de insumos, e de processamento, de armazenamento e de distribuição de produtos agroindustriais (DAVIS; GOLDBERG, 1957). A logística de distribuição de commodities agrícolas tem se tornado cada vez mais um fator crítico de competitividade entre os países exportadores desses produtos (WILSON et al, 2001). Dentre as atividades da logística, o transporte é a atividade responsável pela maior parcela dos custos (FLEURY; WANKE; FUGUEIREDO, 2007). O transporte pode ser realizado nos modais rodoviário, ferroviário e hidroviário, cada um deles possuindo suas vantagens e desvantagens (BALLOU, 2001).

No caso do transporte de grãos, a logística precisa oferecer serviços que atendam as características de conformidade para alimentos, principalmente em relação à perecibilidade, além de um baixo custo operacional. Desse modo, é necessário estudo amplo que considere as vantagens e as desvantagens de cada modal (CAIXETA-FILHO, 2000).

Diante dessas características, a intermodalidade se apresenta como a escolha adequada na logística de produtos alimentícios, porque permite a combinação da maximização das vantagens com a minimização das desvantagens de vários modais nos deslocamentos desse tipo de carga. O elo fundamental que permite a intermodalidade logística é o terminal intermodal, que é o local onde ocorre a mudança do modal de transporte da carga. No entanto, a operacionalização da logística intermodal é complexa e desafiadora (KONINGS; PRIEMUS; NIJKAMP, 2008).

Alguns dos problemas encontrados nas operações dos terminais intermodais estão na contratação das transações de transbordo das cargas. Entre esses problemas está o risco de uma das partes envolvidas na transação querer agir de forma oportunista e prejudicar a outra parte (SCHRAMM, 2012).

As transações que envolvem investimentos em ativos específicos estão mais sujeitas ao risco de oportunismo. Desse modo, para evitar que alguma das partes seja prejudicada, é recomendável que os contratos dessas transações contenham salvaguardas para proteger ambas as partes (WILLIAMSON, 2002).

Diante desse problema, como está a situação de risco nas transações de transbordo de grãos nos terminais intermodais do Brasil?

Com a resposta a essa questão se objetiva descrever a situação de risco no contrato principal de transbordo de cargas de uma amostra de terminais intermodais da cadeia logística de grãos do Brasil, pesquisados por meio da análise da relação entre a especificidade de ativos e a existência de salvaguardas. 
Para auxiliar alcançar esse objetivo, o estudo tem dois objetivos específicos: verificar a existência de salvaguardas no contrato principal de transbordo dos terminais intermodais da cadeia logística de grãos do Brasil que exigiram investimentos em ativos específicos; e identificar qual lado dessas transações está mais exposto ao risco de oportunismo.

Além dessa introdução, o presente artigo está estruturado da seguinte maneira: a próxima seção trata da revisão da literatura sobre risco em transações; em seguida são apresentados o modelo e a hipótese de pesquisa, baseados no esquema de contratação de Williamson (2002); a seção de métodos, que descreve os procedimentos metodológicos; a seção de resultados e discussão, onde os achados da pesquisa são discutidos à luz da literatura e por fim as considerações finais desse estudo.

\section{Risco em Transações}

Um dos primeiros autores a estudar sobre o risco nas atividades econômicas foi Knight (1921), que afirmou que é importante distinguir as situações de risco e de incerteza. Isso porque as situações de risco permitem que as transações ocorram por meio dos mercados, enquanto as situações de incerteza são mais bem conduzidas dentro dos limites da firma. Para esse autor, enquanto a estimação do risco exige o conhecimento de quais alternativas são possíveis de se identificarem em determinada situação, a incerteza ocorre quando não se pode realizar essa classificação completa dos resultados possíveis.

A distinção entre risco e incerteza não surge devido à carência de base para a atribuição de probabilidades, mas sim porque não há nenhuma base válida de qualquer espécie para a classificação dos resultados possíveis. No caso, quando o conhecimento do futuro é parcial ou imperfeito, é impossível classificar os resultados de forma objetiva. Desse modo, a questão fundamental da diferença entre risco e incerteza não está no conhecimento sobre as probabilidades, mas no conhecimento da classificação dos resultados esperados (KNIGHT, 1921).

A análise de risco requer duas etapas de julgamento distintas: a formação de uma estimativa e a estimativa de seu valor. Na primeira etapa, estimam-se os resultados possíveis, para, na etapa posterior, poder estimar a probabilidade de ocorrência de cada um desses resultados. Desse modo, o primeiro passo requer julgamento e intuição em vez de cálculo, sendo mais relevante do que a etapa seguinte, que é a atribuição de probabilidades. Assim, a subjetividade, a objetividade ou a aplicabilidade das probabilidades são de importância secundária, uma vez que as categorias foram estimadas (KNIGHT, 1921).

Outra maneira comum de analisar o risco em transações econômicas é o estudo do problema de hold up (HOLMSTROM; ROBERTS, 1998). Identificado nas transações econômicas pela primeira vez por Klein, Crawford e Alchian (1978), esse problema surge por dois motivos quando um agente precisa fazer algum investimento para transacionar com outro agente. 0 primeiro motivo é que esse investimento é específico para essa transação, o que implica que ele perde valor quando é utilizado em outras transações. O segundo motivo é a impossibilidade de se elaborar um contrato completo, que abranja todos os possíveis problemas que possam surgir com a realização da transação, e que possam afetar a partilha dos retornos do investimento (HOLMSTROM; ROBERTS, 1998; KLEIN; CRAWFORD; ALCHIAN, 1978). 
Devido a essa incompletude dos contratos, após o investimento para a concretização da transação é comum a ocorrência de situações em que se exige - das duas partes - alguma negociação sobre a natureza e sobre os termos das suas transações futuras. Essas negociações ex post permitem que o contratante aproveite o fato de que ele é o único cliente desse determinado produto ou serviço comercializado, para forçar uma redução dos preços praticados pelo contratado. Com isso, o contratante se apropria de parcela dos retornos no investimento de que o fornecedor tinha a esperança de desfrutar (HART, 1995; HOLMSTROM; ROBERTS, 1998).

Desse modo, esse fornecedor contratado pode não estar disposto a investir em ativos específicos, ou pode usar seus recursos para se proteger contra a ameaça de hold up - o que, em última instância, gera ineficiência na transação em ambos os casos (HOLMSTROM; ROBERTS, 1998; KLEIN; CRAWFORD; ALCHIAN, 1978).

O risco em contratos também pode ser analisado por meio da Teoria da Agência (EISENHARDT, 1989). Nessa teoria, que trata do relacionamento de agência, uma parte (chamada de principal) delega trabalho para outra (chamada de agente), que realiza esse trabalho no lugar do principal, numa relação analisada por meio da metáfora de um contrato (JENSEN; MECKLING, 1976).

Essa relação entre principal e agente envolve, entre outras coisas, o problema da partilha de risco nas decisões necessárias para executar o contrato. Isso porque o principal e o agente podem ter diferentes atitudes em relação ao risco, o que, por conseguinte, pode motivá-los a preferir tomar decisões diferentes (EISENHARDT, 1989).

Desse modo, para evitar os problemas decorrentes do relacionamento de agência, a Teoria da Agência se preocupa em propor os melhores arranjos possíveis de contratos. Para tanto, utiliza três tipos de pressupostos: 1) comportamentais, compostos por racionalidade limitada, auto-interesse e aversão ao risco; 2) organizacionais, compostos de conflito de objetivos entre as partes, de eficiência como critério de eficácia, e de assimetria de informação entre principal e agente; e 3) de informação, onde a informação é considerada uma mercadoria (EISENHARDT, 1989).

Outra proposta para tratar o risco em transações é o esquema de contratação, que se configura em um dos elementos da Teoria da Economia dos Custos de Transação (WILLIAMSON, 2002).

Nessa estrutura de análise, duas variáveis são utilizadas para elaborar o melhor tipo de contrato para cada transação: a especificidade do ativo e as salvaguardas. Ela se baseia na ideia de que as transações em que foram realizados investimentos em ativos específicos precisam de salvaguardas para ser confiáveis. Caso contrário, a transação sofre o risco de oportunismo, quando o agente que não investiu no ativo específico barganha condições melhores na negociação, ao buscar diminuir as margens do agente que realizou esse investimento. Essa barganha pode acontecer porque a parte que não realizou os investimentos pode ameaçar não querer transacionar com a parte que investiu nos ativos específicos, pois os investimentos perdem valor em qualquer outra transação (WILLIAMSON, 2002).

Na Figura 1 pode-se observar esse esquema de contratação. A especificidade do ativo é representada por k; assim, quando $k>0$ existe especificidade de ativo na transação, e 
quando $\mathrm{k}=0$ não há essa característica. As salvaguardas são representadas por $\mathrm{s}$, onde $\mathrm{s}>0$ indica a existência de salvaguardas na transação, e $s=0$ mostra que a transação não as possui.

O nó $A$ corresponde às transações onde não existe especificidade de ativos. Trocas comerciais dessa natureza não precisam de contratos e são realizadas no mercado. $O$ nó $B$ mostra transações expostas a risco, porque possuem ativos específicos envolvidos, porém não existem salvaguardas para proteger a parte que realizou o investimento nesses ativos. Já o nó $C$ representa transações com contratos confiáveis, nas quais o investimento em ativos específicos está acompanhado de salvaguardas.

No nó $D$, a especificidade do ativo é tão alta, a incerteza da transação é tão elevada e a elaboração de contratos com salvaguardas adequadas é tão custosa, que a melhor alternativa de governança é a hierarquia; ou seja, a empresa internaliza essa atividade ao invés de contratar outra parte para realizar essa operação (WILLIAMSON, 2002).

Desse modo, por meio dessa estrutura de análise Williamson (2002) propõe que a escolha da melhor forma de contratação para uma transação se baseie nesse modelo, que utiliza a especificidade de ativo e a existência de salvaguardas como fatores fundamentais.

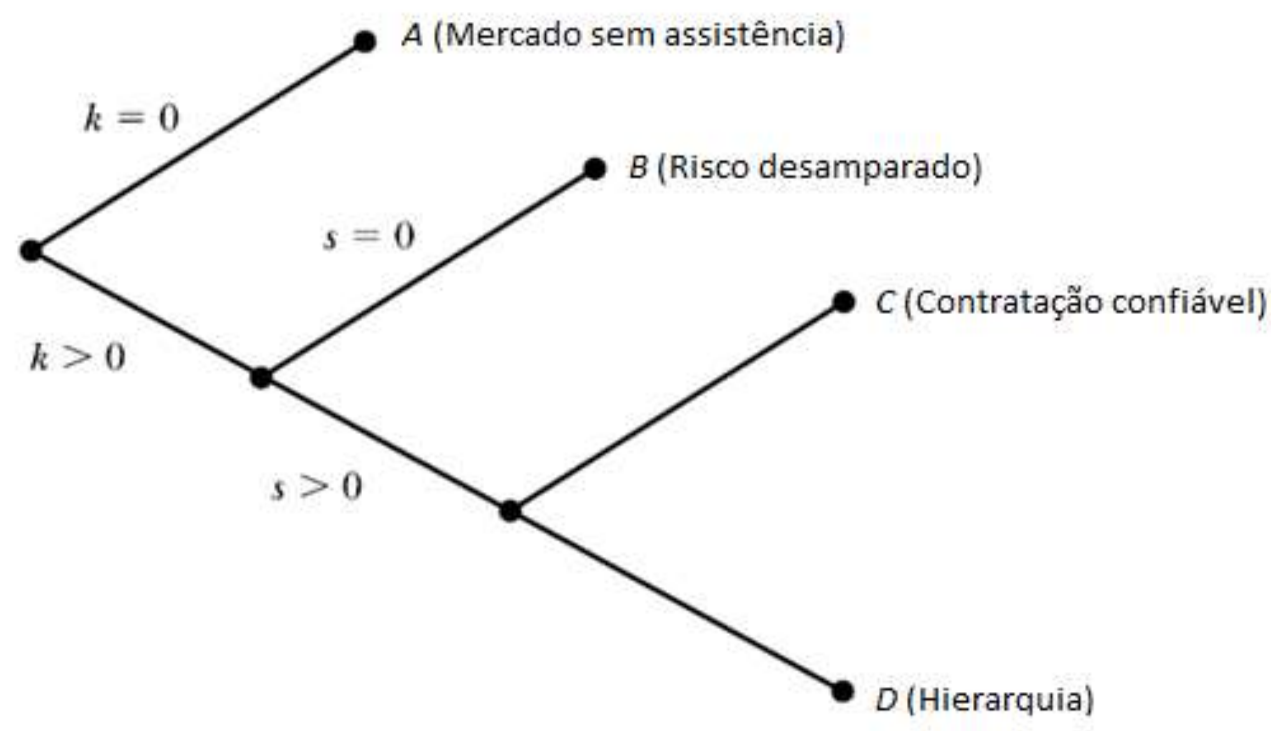

Figura 1 - Esquema de Contratação.

Fonte: Adaptado de Williamson (2002). 


\section{Modelo e Hipótese de Pesquisa}

No Quadro 1 é apresentado o modelo da tabela de contingência usada na presente pesquisa. Formando uma matriz $2 \times 2$, ela contém as duas variáveis empregadas no esquema de contratação de uma transação proposto por Williamson (2002) - "investimentos em ativos específicos" e "salvaguardas" - e suas respectivas duas respostas possíveis (sim ou não).

Quadro 1 - Modelo da tabela de contingência usada na pesquisa

\begin{tabular}{|c|c|c|}
\hline & \multicolumn{2}{|c|}{$\begin{array}{c}\text { Investimentos em } \\
\text { ativos específicos }\end{array}$} \\
\hline Salvaguardas & Sim & Não \\
\hline Sim & a & b \\
\hline Não & c & d \\
\hline
\end{tabular}

Fonte: Elaboração própria

De acordo com o esquema de contratação de uma transação proposto por Williamson (2002), as transações com especificidade de ativos serão asseguradas por salvaguardas para tratar o risco de oportunismo; já as transações sem ativos específicos não terão salvaguardas, pois não há iminência de risco.

Desse modo, nos resultados da presente pesquisa espera-se encontrar uma maior frequência de transações que sigam esse modelo elaborado por Williamson (2002). Ou seja, espera-se que o número de transações na diagonal principal da tabela de contingência seja significativamente maior do que na diagonal secundária.

Assim a hipótese de pesquisa é $H_{0}: a+d>>b+c$

\section{Métodos}

O presente artigo é uma pesquisa descritiva. Segundo Gil (2008), as pesquisas descritivas objetivam descrever características de determinada população ou fenômeno, e estabelecer relações entre as variáveis analisadas. Pesquisas dessa natureza podem se basear na teoria para estabelecer hipóteses que sirvam como guias para a escolha das variáveis a serem mensuradas e analisadas (HAIR Jr et al, 2007).

No caso do presente estudo, pretende-se descrever a situação do risco nos contratos de transbordo de carga dos terminais intermodais da cadeia logística de grãos do Brasil por meio da análise da relação entre as variáveis "especificidade de ativos" e "existência de salvaguardas", de acordo com o esquema de contratação de transações proposto por Williamson (2002). A primeira variável se refere à existência de investimentos necessários para a realização do contrato principal de transbordo de cargas dos terminais logísticos; a segunda variável se refere à existência de salvaguardas nesse contrato. 
Na presente pesquisa utilizou-se a técnica de amostragem não probabilística por conveniência. A amostra desse estudo foi composta por 22 terminais intermodais da cadeia logística de grãos, localizados em 11 estados das cinco regiões geográficas do Brasil. No Quadro 2, pode-se visualizar a relação dos terminais pesquisados e suas respectivas localizações. A coleta dos dados foi feita através da aplicação de questionários estruturados em entrevistas realizadas com os gerentes dos terminais pesquisados.

A análise dos dados foi realizada com o software estatístico MINITAB versão 12 . Foram utilizadas técnicas de estatística descritiva como gráficos de frequência e tabela de contingência. Como as duas variáveis analisadas são de natureza categórica nominal binária, elas possuem como respostas "Sim" ou "Não".

Quadro 2 - Localização dos terminais pesquisados

\begin{tabular}{|c|c|c|c|}
\hline Terminal & Localização & Terminal & Localização \\
\hline CO1 & Cáceres/MT & S2 & Guarapuava/PR \\
\hline CO2 & Cáceres/MT & S3 & Paranaguá/PR \\
\hline CO3 & Alto Taquari/MT & NE1 & Porto Franco/MA \\
\hline CO4 & $\begin{array}{c}\text { Alto } \\
\text { Araguaia/MT }\end{array}$ & NE2 & Porto Franco/MA \\
\hline CO5 & $\begin{array}{c}\text { Campo } \\
\text { Grande/MS }\end{array}$ & NE3 & Porto Franco/MA \\
\hline CO6 & São Simão/GO & NE4 & Salvador/BA \\
\hline CO7 & São Simão/GO & NE5 & Uberlandia/MG \\
\hline CO8 & Maracajú/MS & SE1 & Uberaba/MG \\
\hline CO9 & Ladário/MS & N1 & Santarém/PA \\
\hline S1 & Cascavel/PR & N2 & Porto Velho/RO \\
\hline S2 & Rio Grande/RS & N3 & Porto Nacional/TO \\
\hline
\end{tabular}

Fonte: Elaboração própria 


\section{Resultados e Discussão}

A descrição da frequência das quatro combinações possíveis oriundas da relação das variáveis "investimentos em ativos específicos" e "salvaguardas" dos terminais intermodais pesquisados pode ser vista na tabela de contingência (ver Tabela 1).

Tabela 1 - Tabela de contingência da relação entre ativos específicos e salvaguardas

\begin{tabular}{|c|c|c|}
\hline & \multicolumn{2}{|c|}{$\begin{array}{c}\text { Investimentos em } \\
\text { ativos específicos }\end{array}$} \\
\hline Salvaguardas & Sim & Não \\
\hline Sim & 8 & 8 \\
\hline Não & 4 & 2 \\
\hline
\end{tabular}

Fonte: Elaboração própria

Nessa tabela de contingência, observa-se que: 1) oito contratos de transações tiveram investimentos em ativos específicos acompanhados de salvaguardas; 2) dois contratos de transações não envolveram o investimento em ativos específicos nem tiveram salvaguardas; 3) oito contratos de transações não continham investimentos em ativos específicos e eram acompanhados de salvaguardas; e 4) quatro contratos de transações envolveram o investimento em ativos específicos, mas não tinham salvaguardas.

Desse modo, verifica-se que 12 transações não seguiram o modelo de contratação preconizado por Williamson (2002), enquanto 10 transações se enquadraram no modelo do autor. Esse resultado indica que a hipótese de pesquisa foi rejeitada, pois a maioria das transações não se alinhou com o esquema de contratação que visa a remediação do risco de oportunismo elaborado por Williamson (2002).

Para validar estaticamente a rejeição dessa hipótese, escolheu-se o Teste Exato de Fisher como teste de hipótese não paramétrico, mais adequado quando se testam tabelas de contingências $2 \times 2$ com frequência menor do que cinco em pelo menos uma célula da tabela (FINNDY, 1948).

$\mathrm{O}$ Teste Exato de Fisher bicaudal gerou um p-valor de 0,646. Esse valor indica que as duas variáveis são independentes, ou seja, que não existe nenhuma relação entre investimentos em ativos específicos e salvaguardas. Isso confirma que o esquema de contratação para a remediação do risco de oportunismo proposto por Williamson (2002) não foi validado nos 22 terminais intermodais pesquisados da cadeia logística de grãos do Brasil.

Esse resultado diferente do padrão de contração preconizado por Williamson (2002) pode ter ocorrido porque o setor de serviços logísticos - mais especificamente as transações de transbordo de cargas de terminais intermodais - podem apresentar características particulares distintas da maioria das transações. E, por isso, devem existir mais variáveis para explicar os padrões das transações dessa atividade.

Sobre o risco no investimento em ativos específicos na transação, na tabela de contingência podem-se verificar esses investimentos no contrato principal de 12 dos 22 terminais pesquisados. Em quatro desses 12 contratos de transação o investimento em ativos 
específicos foi realizado pela parte contratante do serviço de transbordo de carga; já em oito transações esses investimentos foram feitos pela parte contratada do serviço, que é o terminal intermodal.

Assim, apurou-se que os contratados na realização do serviço de transbordo de carga, os terminais intermodais estão mais expostos ao risco de hold up do que os clientes desse serviço (ver Figura 2).

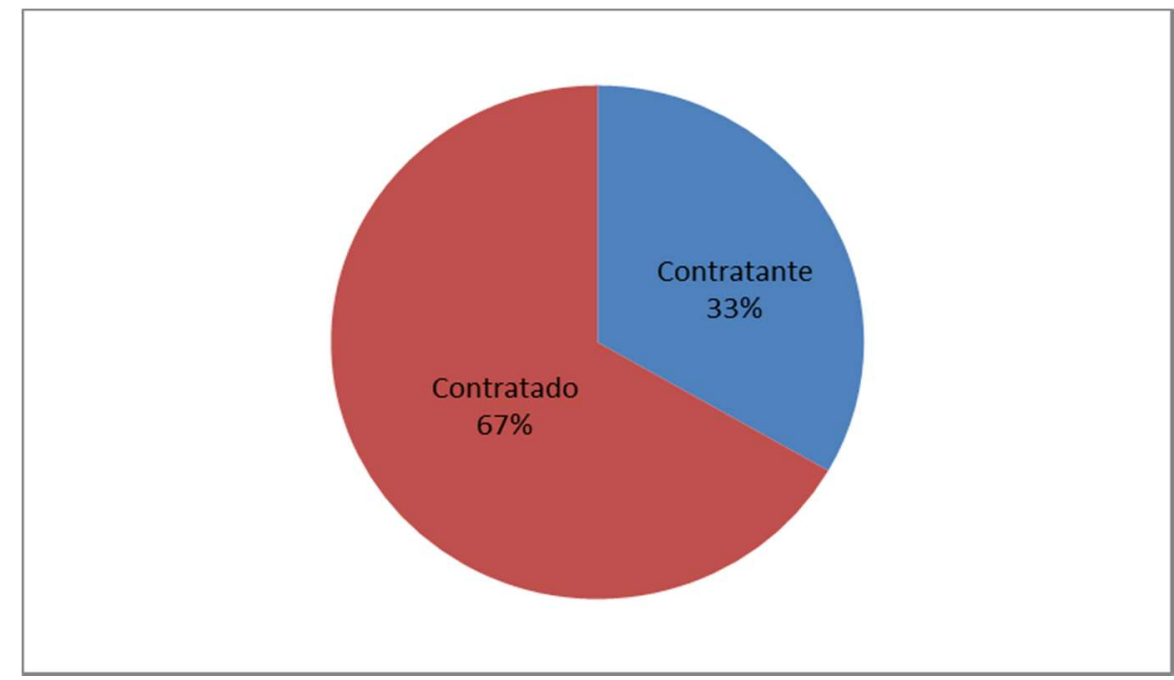

Figura 2 - Partes expostas ao risco nas transações com ativo específico.

Fonte: Elaboração própria

Porém, essa situação é invertida quando se observam quais das partes buscam salvaguardas para se proteger desse risco. Dentre as quatro transações que tiveram investimentos em ativos específicos sem acompanhamento de salvaguardas, em três delas os ativos específicos foram bancados pela parte contratante, e em apenas uma transação o investimento em ativos específicos foi realizado pela parte contratada - ou seja, o terminal intermodal (ver Figura 3). 


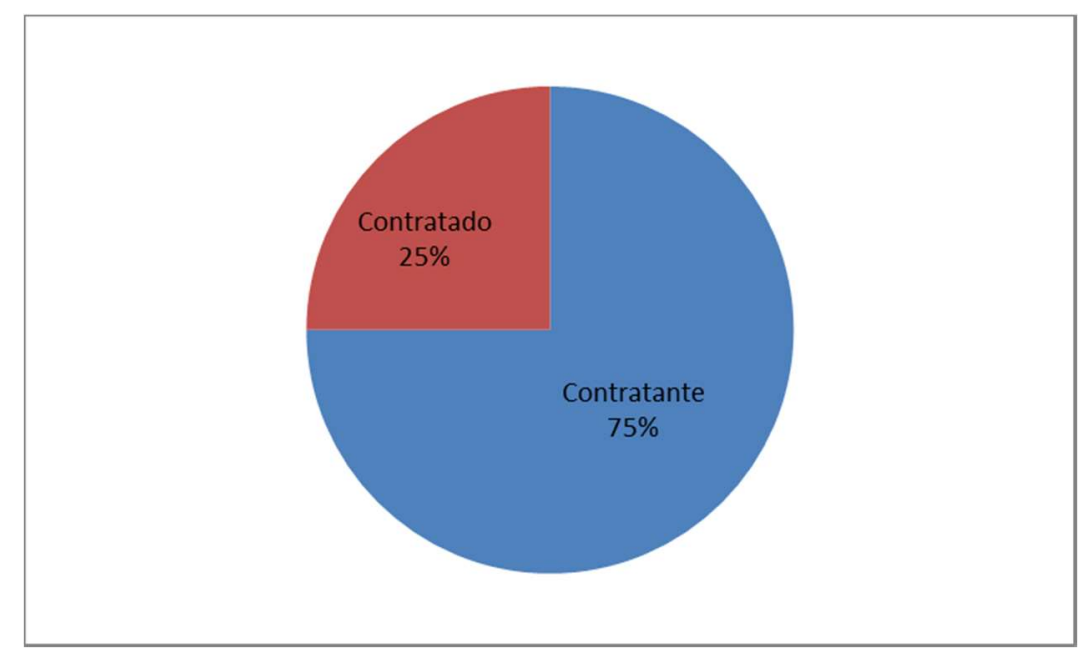

Figura 3 - Partes expostas ao risco nas transações com ativo específico e sem salvaguardas.

Fonte: Elaboração própria

Esse fato também ocorre nas oito transações que envolveram investimentos em ativos específicos juntamente com salvaguardas: em cinco delas o investimento em ativos específicos foi feito pelos terminais intermodais contratados para realizar o serviço logístico, enquanto em duas delas esses investimentos foram realizados pelos contratantes desse serviço e, em uma transação, não foi possível verificar qual parte realizou o investimento (ver Figura 4).

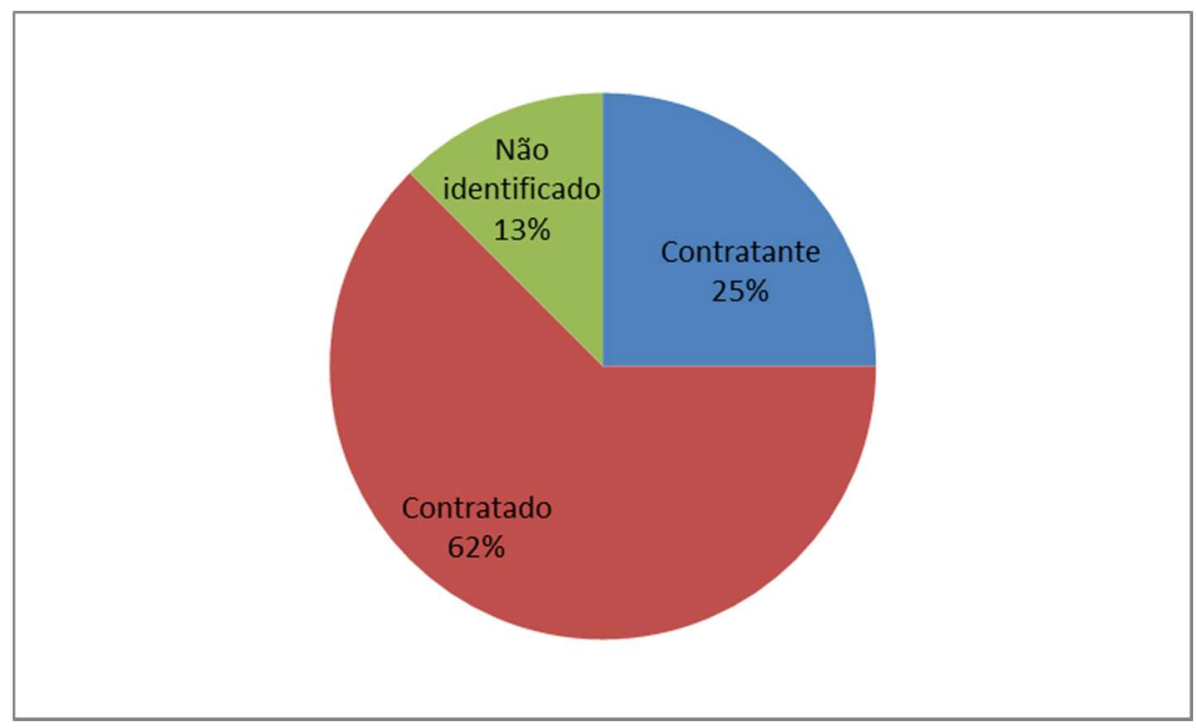

Figura 4 - Partes que protegeram com salvaguardas seus ativos específicos.

Fonte: Elaboração própria

Desse modo, verificou-se que os contratantes dos serviços de transbordo de carregamentos de grãos estão mais expostos ao risco de oportunismo do que os terminais intermodais - ou seja, contratados - nas transações desse serviço, porque eles não protegeram, com salvaguardas, seus investimentos em ativos específicos efetuados para essas transações. 


\section{Considerações Finais}

Nessa pesquisa, verificou-se que a maioria das transações que continham investimentos em ativos específicos estava protegida com salvaguardas. Aliás, apurou-se um excesso de proteção nas transações pesquisadas, pois foram encontradas oito transações com salvaguardas, mas que não tiveram ativos específicos envolvidos. Esse resultado destoante do esquema de contratação proposto por Williamson (2002) indica que as transações analisadas possuem particularidades próprias que não foram levantadas na pesquisa realizada.

Sobre qual das partes envolvidas nas transações de transbordo de grãos estudadas estão mais expostas ao risco de oportunismo, a pesquisa verificou que, em três das quatro transações que tiveram investimentos em ativos específicos e que não tinham salvaguardas, os investimentos em ativos específicos foram realizados pelo contratante do serviço; e, em apenas uma transação, esse investimento foi feito pela parte contratada, que é o terminal intermodal.

Além disso, em cinco das oito transações que envolveram investimentos em ativos específicos juntamente com salvaguardas, esses investimentos foram feitos pelos terminais intermodais contratados; em duas transações os investimentos foram realizados pelos contratantes desse serviço; e, em uma transação, não foi possível verificar qual parte realizou o investimento.

Assim, a pesquisa identificou que os contratantes dos serviços de transbordo de grãos estão mais expostos ao risco de oportunismo do que os terminais intermodais contratados. Isso porque os primeiros não protegeram com salvaguardas seus investimentos em ativos específicos, contrariamente aos terminais intermodais, que protegeram mais seus investimentos nessas transações arriscadas.

Como já indicado, isso implicou a rejeição da hipótese da presente pesquisa de que a maioria das transações pesquisadas se alinharia ao esquema de contratação de transação proposto por Williamson (2002) - isto é, de que as transações que envolvessem investimentos em ativos específicos teriam salvaguardas para proteger esses investimentos contra o risco de oportunismo e as transações que não tivessem investimentos em ativos específicos não precisariam de salvaguardas.

Além do mais, o teste de hipótese não paramétrico aplicado na pesquisa atestou que os investimentos em ativos específicos e salvaguardas não possuem nenhuma relação nas transações analisadas. Desse modo, na amostra utilizada, os pressupostos do esquema de contratação de Williamson (2002) não foram observados.

Esses resultados distintos do modelo teórico que embasou o presente estudo podem ter ocorrido porque as transações pesquisadas - ou seja, os serviços de transbordo de grãos nos terminais intermodais do Brasil - possuem características particulares diferentes da maioria das outras transações.

Uma hipótese para explicar esse comportamento distinto é que as partes dessa transação procuram se proteger de outro risco diferente do problema de hold up, pois somente quatro transações ( $18 \%$ da amostra) sofriam esse risco. Além disso, identificaram-se oito transações sem investimentos específicos e com salvaguardas, o que representa a 
metade das transações com salvaguardas encontradas no estudo. No entanto, a procura de explicações foge do escopo da pesquisa.

Outra limitação da pesquisa é que nela foi utilizada amostra não probabilística, o que significa que seus resultados não podem ser generalizados para toda a população dos terminais intermodais da cadeia logística de grãos do Brasil.

Desse modo, diante dos resultados e limitações dessa pesquisa, recomendam-se mais estudos tanto de natureza qualitativa quanto de natureza quantitativa, para entender melhor os padrões de contratação das transações dos serviços de transbordo de grãos nos terminais intermodais brasileiros.

\section{Referências}

BALLOU, R. H. Gerenciamento da cadeia de suprimentos: Planejamento, organização e logística empresarial. 4. ed. Porto Alegre: Bookman, 2001.

CEPEA - CENTRO DE ESTUDOS AVANÇADOS EM ECONOMIA APLICADA. PIB do agronegócio: dados de 1994 a 2015. Disponível em: <http://www.cepea.esalq.usp.br/br/pib-do-agronegociobrasileiro.aspx>. Acesso em: 01 fev. 2015.

CAIXETA FILHO, J .V. Sistemas de transporte e logística: conceitos básicos e modelagem matemática. In: ZYLBERSZTAJN, D.; NEVES, M. F. Economia e gestão dos negócios agroalimentares. São Paulo: Pioneira, 2000.

CONAB - COMPANHIA NACIONAL DE ABASTECIMENTO. Acompanhamento da safra brasileira: grãos, oitavo levantamento, maio/2012. Brasília: Conab, 2012. Disponível

em:<http://www.conab.gov.br/OlalaCMS/uploads/arquivos/12_05_10_08_49_52_boletim_maio_20 12.pdf >. Acesso em: 23 mai. 2012.

DAVIS, J. H.; GOLDBERG, R. A. A concept of agribusiness. Boston: Harvard University, Graduate School of Business Administration, 1957.

EISENHARDT, K. M. Agency Theory: An Assessment and Review, The Academy of Management Review, v. 14, n. 1, p. 57-74, 1989.

FINNDY, D. J. The Fisher-Yates test of significance in $2 \times 2$ contingency tables. Biometrika v. 35, n.1/2, p.145-156, 1948.

FLEURY, P. F.; WANKE, P.; FIGUEIREDO, K. F. Logística empresarial: a perspectiva

brasileira. São Paulo: Atlas, 2007.

GIL, A. C. Métodos e técnicas em pesquisa social. 6. ed. São Paulo: Atlas, 2008.

HAIR Jr., J. et al. Fundamentos de Métodos de Pesquisa em Administração. Porto Alegre: Bookman, 2007, $471 \mathrm{p}$.

HART, O. Firms, Contracts, and Financial Structure. Oxford: Oxford University Press, 1995.

HOLMSTROM, B.; ROBERTS, J. The Boundaries of the Firm Revisited. Journal of Economic Perspectives, v. 12, n. 4, p. 73-94, 1998.

JENSEN, M.; MECKLING, W. Theory of the firm: managerial behavior, agency costs and ownership structure. Journal of Financial Economics, v. 3, n. 4, p. 305-360, 1976.

KLEIN, B; CRAWFORD, R.; ALCHIAN, A. Vertical Integration, Appropriable Rents, and the Competitive Contracting Process, Journal of Law and Economics, v. 21, p. 297-326, 1978.

KNIGHT, F. Risk, uncertainty and profit. New York: Augustus Kelley, 1921.

KONINGS, J.; PRIEMUS, H.; NIJKAMP, P. (eds.). The Future of Intermodal Freight Transport: an overview. Edward Elgar Publishing: Cheltenham, UK, 2008. 
LANGLOIS, R.; COSGEL, M. M. Frank Knight on Risk, Uncertainty, and the Firm: A New Interpretation. Economic Inquiry, Western Economic Association International, v. 31, n.3, p. 456-65, 1993.

MAPA - MINISTÉRIO DA AGRICULTURA, PECUÁRIA E ABASTECIMENTO. Estatísticas e dados básicos de economia, $2012 . \quad$ Disponível em:

<http://www.agricultura.gov.br/arq_editor/file/vegetal/Estatistica/Estat\%C3\%ADticas\%20e\%

20Dados\%20B\%C3\%A1sicos\%20de\%20Economia\%20Agr\%C3\%ADcola/Pasta\%20Janeiro-

2012.pdf>. Acesso em: 10 jan. 2013.

MELTZER, A. H. Rational Expectations, Risk, Uncertainty, and Market Responses, Paper 751, Tepper School of Business, 1982.

PEREIRA, J. Análise de dados qualitativos: estratégias metodológicas para as Ciências da Saúde, Humanas e Sociais. 3. ed. São Paulo: Edusp, 2004.

SCHRAMM, H. Freight Forwarder's Intermediary Role in Multimodal Transport Chains: A Social Network Approach. Berlin: Physica-Verlag, 2012.

WILLIAMSON, O. The Theory of the Firm as Governance Structure: From Choice to Contract. Journal of Economic Perspectives, v. 16, n.3, p. 171-195, 2002.

WILSON, W. et al. Logistics and Supply Chain Strategies in Grain Exporting. Agribusiness \& Applied Economics Report No. 457. Department of Agribusiness and Applied Economics, North Dakota State University, Fargo, North Dakota, 2001. 